\title{
Pengaruh Faktor Situasional Terhadap Keputusan Pembelian Di Harvard English Course Bandung
}

\author{
Nurlela1, Fauzan Aziz ${ }^{2}$ \\ ${ }^{1}$ Mahasiswa Program Studi Administrasi Bisnis \\ ${ }^{2}$ Dosen Program Studi Administrasi Bisnis \\ Universitas Sangga Buana YPKP Bandung \\ lelaiskand@gmail.com
}

\begin{abstract}
ABSTRAK
Penelitian ini dilakukan untuk mengetahui apakah faktor situasional terhadap keputusan pembelian di Harvard English Course Bandung. Tujuan penelitian ini adalah untuk mengetahui dan menganalisis bagaimana faktor situasional terhadap keputusan pembelian konsumen, serta besarnya pengaruh faktor situasional secara signifikan terhadap keputusan pembelian di Harvard English Course Bandung. Penelitian ini menggunakan metode asosiatif dengan pendekatan kuantitatif. Pengambilan sampel dilakukan dengan metode probability sampling jenis random sampling, dengan jumlah responden sebanyak 100 orang. Teknik analisis data yang digunakan adalah analisis inferensial, method of succesisive interval (MSI) dan Partial Least Square (PLS). Berdasarkan hasil pengujian hipotesis, faktor situasional berpengaruh signifikan terhadap keputusan pembelian di Harvard English Course Bandung. Faktor situasional di Harvard English Course Bandung sudah masuk kedalam kategori cukup baik, namun ada beberapa item yang perlu diperbaiki seperti adanya pengajar asing, dan mengatur jadwal kursus yang flexible.
\end{abstract}

Kata Kunci: faktor situasional, keputusan pembelian, physical surroundings, social surroundings, temporal perspectives, task definition, antecedent states.

\begin{abstract}
This study was conducted to determine the effect of situational factor on consumer decision at english course Harvard English Course Bandung. The purpose of this study was to determine and analyze the situational factor of customer decision, and the influence of the situational factor of customer decision at Harvard English Course Bandung. This study was associative method with quantitative. Sampling technique used was probability sampling type random sampling, with the total number of 100 respondents. The data was analyzed inferential, method of succesive interval (MSI) and Partial Least Square (PLS). Based on the results of simultaneous hypothesis testing, situational factor significantly influence customers' decision at Harvard English Course Bandung. Situational factors at Harvard English Course Bandung have entered into quite good categories, but there are some items that need to be improved such as the presence of foreign instructors, and arrange a flexible course schedule
\end{abstract}

Keywords: situational factor, customer decision, physical surroundings, social surroundings, temporal perspectives, task definition, antecedent states. 


\section{PENDAHULUAN}

Bahasa Inggris adalah bahasa internasional yang digunakan sebagai bahasa komunikasi penghubung antar bangsa dan negara di seluruh dunia. Kemampuan berbahasa Inggris merupakan salah satu kemampuan yang sangat penting, karena Bahasa Inggris sudah menjadi bahasa universal yang digunakan dalam pendidikan, teknologi, perdagangan, serta Bahasa Inggris pertama kali dituturkan di Inggris dan saat ini merupakan bahasa yang paling umum digunakan di dunia. Banyak sekali cara untuk belajar agar dapat menguasai bahasa inggris, salah satunya adalah dengan mengikuti kursus bahasa inggris yang disesuaikan dengan kebutuhan atau tingkat kemampuan yang telah dimiliki sebelumnya. Tempat kursus bahasa inggris tentu saja dapat kita temui di kota Bandung. Terdapat 15 tempat kursus bahasa inggris yang terdaftar di kota Bandung. Salah satu english course yang masih bertahan hingga saat ini yaitu Harvard English Course.

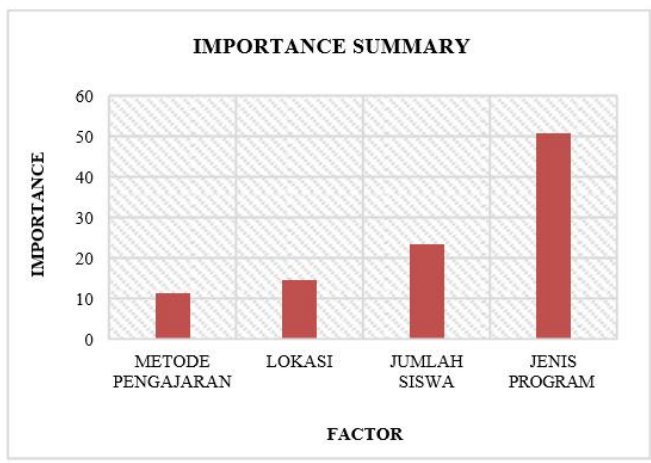

Sumber : Rhea Pagita, Peggy Hariawan (2015:4)

Gambar 1. Faktor yang Mempengaruhi

Konsumen Memilih Tempat Kursus

Harvard English Course masih menjadi tempat yang dipilih konsumen sebagai tempat kursus dari tahun 1979. Adapun kriteria tempat kursus bahasa inggris yang diinginkan oleh konsumen menurut jurnal yang disusun oleh Rhea Pagita dan Peggy Hariawan yang berjudul Analisis Preferensi Konsumen Terhadap Tempat Kursus Bahasa Inggris di Bandung, diantaranya adalah: metode pengajarannya yang menarik/pengajarnya yang ahli, lokasi yang terjangkau, dan mempunyai banyak variasi program yang tersedia. Pada gambar 1 diketahui bahwa siswa SMA kota Bandung pada tahun 2015 dengan jumlah 23,487 mempengaruhi konsumen dalam membuat keputusan pembelian.

Keputusan pembelian yang dimaksud adalah keputusan pembelian jasa pada bidang layanan pendidikan dalam hal belajar bahasa inggris. Konsumen lebih menyukai kondisi kelas yang tidak terlalu ramai ataupun sepi dengan jumlah siswa sebanyak $10-20$ orang perkelas. Hal tersebut temasuk kedalam salah satu faktor situasional yaitu lingkungan fisik, dimana suasana ramai pada suatu tempat mempengaruhi seseorang dalam memilih keputusan. Pada gambar 1 diketahui bahwa lokasi juga merupakan faktor yang mempengaruhi konsumen dalam memilih tempat kursus.

Lokasi merupakan salah satu faktor situasional yaitu lingkungan fisik. Metode pengajaran juga mempengaruhi konsumen dalam memilih tempat kursus. Metode pengajaran termasuk salah satu faktor situasional yaitu definisi tugas. Menurut data diatas dapat kita ketahui bahwa faktor situasional mempengaruhi konsumen dalam keputusan pembelian. Keputusan pembelian yang dimaksud merupakan pembelian jasa pada bidang layanan pendidikan dalam hal belajar bahasa inggris. Hal tersebut memberikan dampak pada jumlah peserta didik di Harvard English.

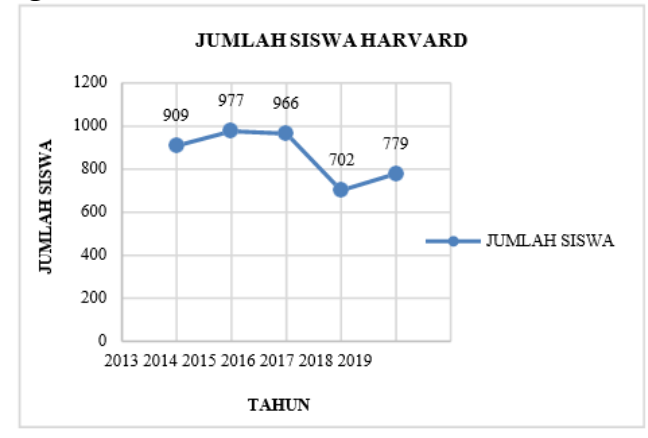

Sumber : Harvard English Course (2018)

\section{Gambar 2. Jumlah Siswa Harvard}

Berdasarkan informasi pada garmbar 2 diketahui bahwa siswa Harvard pada tahun 2017 mengalami penurunan. Pada 
tahun 2017 jumlah siswa Harvard yaitu 702 siswa, sedangkan jumlah siswa Harvard pada tahun 2016 tercatat sejumlah 966 siswa. Akan tetapi jumlah siswa Harvard pada tahun 2018 bertambah menjadi 779 siswa. Harvard English Course harus dapat menghadapi persaingan yang semakin ketat dalam memperebutkan jumlah konsumen yang ada. Pihak perusahaan harus dapat memahami perilaku konsumen secara keseluruhan agar dapat mempertahankan kelangsungan hidup juga dapat merumuskan strategi pemasaran dengan tepat. Untuk memahami perilaku konsumen, kita harus tahu tentang konsumen, tentang rangsangan objek primer, seperti produk atau iklan yang konsumen respon, dan tentang situasi dimana respon itu terjadi (Hawkins, et al., 2016). Situasi tersebut dapat digambarkan pada sejumlah dimensi yang dapat menentukan pengaruh mereka terhadap perilaku konsumen untuk menentukan keputusan mereka dalam memilih tempat kursus.

Kriteria yang dapat mempengaruhi konsumen dalam memilih tempat kursus diantaranya adalah jumlah siswa yang tidak terlalu ramai/sepi dalam 1 kelas, lokasi yang dekat dengan sekolah, dan metode pengajaran yang dilakukan oleh pengajar ahli. Kriteria tersebut termasuk dalam faktor situasional. Faktor situasional tersebut menjadi suatu alasan penurunan jumlah siswa Harvard dari tahun ke tahun.

Berdasarkan latar belakang yang telah dijelaskan diatas, maka penulis tertarik melakukan penelitian dengan judul "Pengaruh Faktor Situasional Terhadap Keputusan Pembelian di Harvard English Course Bandung”. Keputusan pembelian yang dimaksud dalam penelitian ini adalah keputusan pembelian jasa pada bidang layanan pendidikan dalam hal belajar bahasa inggris.

\section{TINJAUAN PUSTAKA}

\section{Faktor Situasional}

Perilaku konsumen pada saat pembelian sulit untuk diprediksi, dimana seringkali konsumen membeli produk tidak sebagai rutinitas tetapi sebagai pembelian berdasarkan situasi yang diinginkan. Menurut Hawkins dan Mothersbaugh (2016:470) faktor situasional adalah all those factors particular to a time and place that do not follow from a knowledge of the stable attributes of the consumer and the stimulus and that have an effect on current behavior.

Faktor situasional merupakan faktor faktor tertentu yang berhubungan dengan waktu dan tempat dan tidak berasal dari dalam diri mereka, dan dari merek atau dari produk yang dipasarkan, kondisi tersebut muncul tiba - tiba yang mana dalam hal tersebut dapat mempengaruhi seseorang dalam melakukan kegiatan konsumsi. Menurut Hawkins dan Mothersbaugh (2016:474) terdapat 5 dimensi atau karakteristik dalam faktor situasional diantaranya adalah physical surroundings, social surroundings, temporal perspectives, task definition, and antecedent states.

a. Lingkungan Fisik (Physical

Surroundings)

Menurut Hawkins dan Mothersbaugh (2016:474) mengemukakan bahwa: external factors such as the architecture, arrangement, can be in affecting consumers shopping experiences. Physical surroundings include decor, sounds, aromas, lighting, weather, and configurations of merchandise or other materials surrounding the stimulus object. Faktor eksternal seperti arsitektur, penataan dapat mempengaruhi pengalaman belanja konsumen. Lingkungan fisik merupakan faktor yang paling terlihat, karena hal ini meliputi dekorasi, suara, aroma, pencahayaan, cuaca dan konfigurasi barang dagangan. 


\section{b. Lingkungan Sosial (Social Surroundings)}

Menurut Hawkins dan Mothersbaugh (2016:477) mengatakan bahwa: social surroundings are the other individuals present in the particular situasion. People's actions are frequently influenced by those around them. Lingkungan sosial merupakan kehadiran orang lain yang ada selama proses konsumsi. Dengan adanya kehadiran orang lain yang menemani maupun memberi saran dalam memilih produk/jasa, hal tersebut dapat mendorong konsumen menentukan produk/jasa mana yang akan dipilih.

\section{c. Perspektif Waktu (Temporal Perspectives)}

Waktu dapat diukur sehubungan dengan beberapa kejadian yang terjadi di masa lalu atau di masa datang. Menurut Hawkins dan Mothersbaugh (2016:480) mengatakan bahwa: temporal perspectives are situational characteristics that deal with the effect of time on consumer behavior. Time as situational factor can manifest itself in a number of ways. The amount of time available for the purchase has a substantial impact on the consumer decision process. Waktu merupakan karakteristik situasional yang berhubungan dengan pengaruh waktu pada perilaku konsumen, misalnya kejadian tertentu ketika perilaku pembelian terjadi yang ditentukan dalam satuan - satuan dari jam, hari, bulan hingga sampai pergantian musim. Jumlah waktu yang tersedia untuk pembelian memiliki dampak besar pada proses keputusan konsumen. Secara umum, semakin sedikit waktu yang tersedia, maka semakin pendek konsumen dalam mencari informasi.

\section{d. Definisi Tugas (Task Definition)}

Menurut Hawkins dan Mothersbaugh (2016:481) mengatakan bahwa: task definition is the reason the consumption activity is occurring. Consumer use different shopping strategies and purchase criteria when shopping for gift versus shopping for the same item for selfuse. Definisi tugas merupakan alasan kegiatan konsumsi terjadi. Konsumen menggunakan berbagai strategi belanja dan mempunyai beberapa kriteria pembelian, misalnya tujuan mereka berbelanja untuk membeli suatu hadiah atau berbelanja untuk digunakan sendiri. Definisi tugas juga menggambarkan peran - peran pembeli dan penjual yang berbeda yang dirasakan oleh individu. Definisi tugas merupakan faktor situasi yang mencakup niat/maksud konsumen atau kebutuhan konsumen untuk memilih, berbelanja atau mendapatkan informasi mengenai produk/jasa.

\section{e. Suasana Hati (Antecedent States)}

Hawkins \& Mothersbaugh (2016:481) mengemukakan bahwa: features of the individual person that are not lasting characteristics, such as momentary moods or conditions, are called antecedent states. Suasana hati merupakan ciri dari individu yang bersifat sementara, seperti keadaan yang sedang dialami oleh individu tersebut. Menurut Hawkins dan Mothersbaugh (2016:481) mengatakan bahwa: antecedent states are features of individual person that are not lasting characteristics, such as momentary moods or conditions. Suasana hati juga dapat menjadi peran penting dalam situasi komunikasi. Suasana hati konsumen yang positif akan memudahkan penjual dalam memberikan informasi, karena konsumen akan merasa senang dan mudah untuk menerima informasi yang disampaikan.

\section{Keputusan Pembelian}

Menurut Kotler \& Keller (2009:184) mengemukakan bahwa: keputusan pembelian pelanggan secara penuh merupakan suatu proses yang berasal dari semua pengalaman mereka dalam pembelajaran, memilih, menggunakan, dan bahkan dalam mendisposisikan produk. Keputusan pembelian merupakan keputusan konsumen dimana konsumen melakukan pembelian terhadap produk/jasa dari berbagai alternatif pilihan 
yang ada. Keputusan pembelian juga merupakan suatu tahapan dalam proses keputusan pembelian yang dimulai dari tahap pengenalan masalah. Ada lima tahap proses keputusan pembelian konsumen menurut Kotler dan Keller (2016:195), yaitu:

\section{a. Pengenalan Masalah (Problem Recognition)}

Proses pembelian dimulai ketika pembeli menyadari masalah atau kebutuhan yang dirangsang oleh rangsangan internal atau eksternal. Pada tahap pengenalan masalah ini pemasar perlu mengenal berbagai hal yang dapat menggerakkan kebutuhan atau minat konsumen. Para pemasar perlu mengidentifikasi apa yang menjadi kebutuhan atau apa masalah yang konsumen hadapi. Kebutuhan atau masalah tersebut dapat menyebabkan konsumen dalam mencari produk yang dapat memenuhi kebutuhannya.

b. Pencarian Informasi (Information Search)

Konsumen yang ingin memenuhi kebutuhannya akan mencari informasi mengenai produk/jasa. Seseorang konsumen yang sudah tertarik terhadap suatu produk/jasa akan mencari informasi lebih banyak. Konsumen dapat memperoleh informasi dari beberapa sumber yaitu: sumber pribadi (keluarga, teman, tetangga, rekan), komersial (iklan, situs, web, wiraniaga, penyalur, kemasan, tampilan), publik (media elektronik, media cetak), dan sumber pengalaman (penanganan, pemeriksaan, dan penanganan produk).

c. Evaluasi Alternatif (Evaluation of Alternatives)

Setelah mencari informasi, konsumen akan dihadapkan pada beberapa pilihan produk/jasa yang akan dibelinya. Pada tahap ini konsumen melakukan evaluasi terhadap barang/ jasa mana yang paling cocok untuk dibeli sesuai dengan kebutuhan dan keinginannya. d. Keputusan Pembelian (Purchase Decision)

Pada tahap ini konsumen membentuk maksud untuk membeli produk yang sesuai dengan kebutuhan dan keinginannya. Keputusan pembelian dipengaruhi oleh dua faktor, yaitu faktor internal dan faktor eksternal. Faktor internal berkaitan dengan persepsi konsumen terhadap merek atau produk yang paling disukai. Sedangkan faktor eksternal berkaitan dengan sikap orang lain dan situasi yang tidak terduga.

e. Perilaku Pasca Pembelian

(Postpurchase Behavior)

Setelah membeli produk/jasa, konsumen akan melakukan evaluasi produk yang dikonsumsi atau jasa yang digunakan tersebut. Evaluasi produk yang dikonsumsi mengarah pada respon puas atau tidak puas setelah menggunakan produk. Pada tahap ini konsumen akan mempertimbangkan apakah melanjutkan membeli produk/jasa tersebut atau memilih alternatif lain.

\section{METODOLOGI}

Metode penelitian yang digunakan dalam penelitian ini adalaha metode asosiatif dengan pendekatan kuantitatif. Pengambilan sampel dilakukan dengan metode probability sampling jenis random sampling, dengan jumlah responden sebanyak 100 orang. Teknik analisis data yang digunakan adalah analisis inferensial, method of succesisive interval (MSI) dan Partial Least Square (PLS). 


\section{HASIL DAN PEMBAHASAN}

\section{Faktor Situasional}

Tabel 3.1: Skor Jawaban Responden

Terhadap Item Pernyataan Variabel Faktor Situasional (X)

\begin{tabular}{|c|c|c|c|c|c|c|c|c|c|c|}
\hline \multirow[b]{2}{*}{ No } & \multirow{2}{*}{$\begin{array}{c}\text { Item } \\
\text { Pertanyaan } \\
\text { Variabel X }\end{array}$} & & \multicolumn{5}{|c|}{ Jawaban Responden } & \multirow[b]{2}{*}{$\begin{array}{c}\text { Skor } \\
\text { Akrual }\end{array}$} & \multirow[b]{2}{*}{$\begin{array}{l}\text { Skor } \\
\text { Ideal }\end{array}$} & \multirow[b]{2}{*}{$\%$} \\
\hline & & & 5 & 4 & 3 & 2 & 1 & & & \\
\hline \multirow[t]{2}{*}{1} & Item 1 & $\mathrm{~F}$ & 7 & 45 & 34 & 5 & 9 & 336 & 500 & $67,2 \%$ \\
\hline & & $\%$ & $7 \%$ & $45 \%$ & $34 \%$ & $5 \%$ & $9 \%$ & & & \\
\hline \multirow[t]{2}{*}{2} & Item 2 & $\mathrm{~F}$ & 1 & 43 & 41 & 12 & 3 & 327 & 500 & $65,4 \%$ \\
\hline & & $\%$ & $1 \%$ & $43 \%$ & $41 \%$ & $12 \%$ & $3 \%$ & & & \\
\hline \multirow[t]{2}{*}{3} & Item 3 & $\mathrm{~F}$ & 0 & 41 & 42 & 13 & 4 & 320 & 500 & $64,0 \%$ \\
\hline & & $\%$ & $0 \%$ & $41 \%$ & $42 \%$ & $13 \%$ & $4 \%$ & & & \\
\hline \multirow[t]{2}{*}{4} & Item 4 & $\mathrm{~F}$ & 2 & 38 & 42 & 15 & 3 & 321 & 500 & $64,2 \%$ \\
\hline & & $\%$ & $2 \%$ & $38 \%$ & $42 \%$ & $15 \%$ & $3 \%$ & & & \\
\hline \multirow[t]{2}{*}{5} & Item 5 & $\mathrm{~F}$ & 1 & 39 & 49 & 8 & 3 & 327 & 500 & $65,4 \%$ \\
\hline & & $\%$ & $1 \%$ & $39 \%$ & $49 \%$ & $8 \%$ & $3 \%$ & & & \\
\hline \multirow[t]{2}{*}{6} & Item 6 & $\mathrm{~F}$ & 1 & 43 & 48 & 7 & 1 & 336 & 500 & $67,2 \%$ \\
\hline & & $\%$ & $1 \%$ & $43 \%$ & $48 \%$ & $7 \%$ & $1 \%$ & & & \\
\hline \multirow[t]{2}{*}{7} & Item 7 & $\mathrm{~F}$ & 1 & 46 & 48 & 5 & 0 & 343 & 500 & $68,6 \%$ \\
\hline & & $\%$ & $1 \%$ & $46 \%$ & $48 \%$ & $5 \%$ & $0 \%$ & & & \\
\hline \multirow[t]{2}{*}{8} & Item 8 & $\mathrm{~F}$ & 3 & 33 & 59 & 4 & 4 & 336 & 500 & $67,2 \%$ \\
\hline & & $\%$ & $3 \%$ & $33 \%$ & $59 \%$ & $4 \%$ & $4 \%$ & & & \\
\hline \multirow[t]{2}{*}{9} & Item 9 & $\mathrm{~F}$ & 1 & 38 & 55 & 6 & 0 & 334 & 500 & $66,8 \%$ \\
\hline & & $\%$ & $1 \%$ & $38 \%$ & $55 \%$ & $6 \%$ & $0 \%$ & & & \\
\hline \multirow[t]{2}{*}{10} & Item 10 & $\mathrm{~F}$ & 1 & 36 & 59 & 4 & 0 & 334 & 500 & $66,8 \%$ \\
\hline & & $\%$ & $1 \%$ & $36 \%$ & $59 \%$ & $4 \%$ & $0 \%$ & & & \\
\hline \multirow[t]{2}{*}{11} & Item 11 & $\mathrm{~F}$ & 0 & 41 & 53 & 6 & 0 & 335 & 500 & $67,0 \%$ \\
\hline & & $\%$ & $0 \%$ & $41 \%$ & $53 \%$ & $6 \%$ & $0 \%$ & & & \\
\hline \multirow[t]{2}{*}{12} & Item 12 & $\mathrm{~F}$ & 0 & 40 & 52 & 8 & 0 & 332 & 500 & $66,4 \%$ \\
\hline & & $\%$ & $0 \%$ & $40 \%$ & $52 \%$ & $8 \%$ & $0 \%$ & & & \\
\hline \multirow[t]{2}{*}{13} & Item 13 & $\mathrm{~F}$ & 0 & 38 & 57 & 5 & 0 & 333 & 500 & $66,6 \%$ \\
\hline & & $\%$ & $0 \%$ & $38 \%$ & $57 \%$ & $5 \%$ & $0 \%$ & & & \\
\hline \multirow[t]{2}{*}{14} & Item 14 & $\mathrm{~F}$ & 0 & 37 & 53 & 9 & 1 & 326 & 500 & $65,2 \%$ \\
\hline & & $\%$ & $0 \%$ & $37 \%$ & $53 \%$ & $9 \%$ & $1 \%$ & & & \\
\hline \multirow{3}{*}{\multicolumn{2}{|c|}{ Akumulasi Jawaba }} & $\mathrm{F}$ & 18 & 558 & 692 & 107 & 28 & 4640 & 7000 & $66,3 \%$ \\
\hline & & & $18 \%$ & $558 \%$ & $692 \%$ & $107 \%$ & $28 \%$ & & & \\
\hline & & & $1,3 \%$ & $39,8 \%$ & $49,3 \%$ & $7,6 \%$ & $2,0 \%$ & & & \\
\hline
\end{tabular}

Sumber: data primer yang diolah, (2019)

Secara garis besar, letak minat transaksional dapat dilihat pada gambar 3.1 .

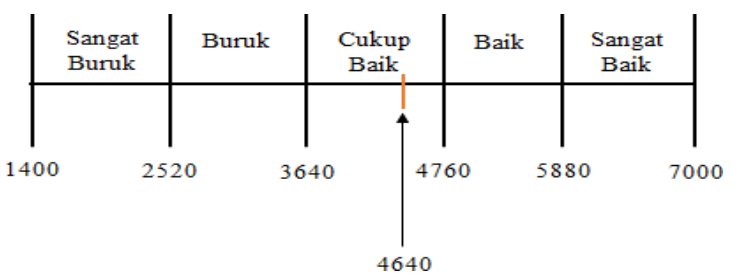

Gambar 3.1 Skala Kontinum Variabel Faktor Situasional

Berdasarkan gambar 3.1 diatas menunjukan bahwa data yang diperoleh dari hasil perhitungan pengkategorian untuk skor total faktor situasional terletak antara rentang 3640 dan 4760. Dengan demikian, penilaian para responden terhadap faktor situasional termasuk dalam kategori penilaian cukup baik.

\section{Keputusan Pembelian}

Tabel 3.2 Skor Jawaban Responden Terhadap Item Pernyataan Variabel Keputusan

Pembelian (Y)

\begin{tabular}{|c|c|c|c|c|c|c|c|c|c|c|}
\hline \multirow[b]{2}{*}{ No } & \multirow{2}{*}{$\begin{array}{c}\text { Item } \\
\text { Pertanyaan } \\
\text { Variabel Y }\end{array}$} & & \multicolumn{5}{|c|}{ Jawaban Responden } & \multirow[b]{2}{*}{$\begin{array}{c}\text { Skor } \\
\text { Akrual }\end{array}$} & \multirow[b]{2}{*}{$\begin{array}{l}\text { Skor } \\
\text { Ideal }\end{array}$} & \multirow[b]{2}{*}{$\%$} \\
\hline & & & 5 & 4 & 3 & 2 & 1 & & & \\
\hline \multirow[t]{2}{*}{1} & Item 1 & $\mathrm{~F}$ & 0 & 48 & 52 & 0 & 0 & 348 & 500 & $69,6 \%$ \\
\hline & & $\%$ & $0 \%$ & $48 \%$ & $52 \%$ & $0 \%$ & $0 \%$ & & & \\
\hline \multirow[t]{2}{*}{2} & Item 2 & $\mathrm{~F}$ & 0 & 44 & 51 & 5 & 0 & 339 & 500 & $67,8 \%$ \\
\hline & & $\%$ & $0 \%$ & $44 \%$ & $51 \%$ & $5 \%$ & $0 \%$ & & & \\
\hline \multirow[t]{2}{*}{3} & Item 3 & $\mathrm{~F}$ & 0 & 42 & 54 & 4 & 0 & 338 & 500 & $67,6 \%$ \\
\hline & & $\%$ & $0 \%$ & $42 \%$ & $54 \%$ & $4 \%$ & $0 \%$ & & & \\
\hline \multirow[t]{2}{*}{4} & Item 4 & $\mathrm{~F}$ & 0 & 36 & 61 & 2 & 1 & 332 & 500 & $66,4 \%$ \\
\hline & & $\%$ & $0 \%$ & $36 \%$ & $61 \%$ & $2 \%$ & $1 \%$ & & & \\
\hline \multirow[t]{2}{*}{5} & Item 5 & $\mathrm{~F}$ & 0 & 37 & 57 & 6 & 0 & 331 & 500 & $66,2 \%$ \\
\hline & & $\%$ & $0 \%$ & $37 \%$ & $57 \%$ & $6 \%$ & $0 \%$ & & & \\
\hline \multirow[t]{2}{*}{6} & Item 6 & $\mathrm{~F}$ & 0 & 10 & 48 & 36 & 6 & 262 & 500 & $52,4 \%$ \\
\hline & & $\%$ & $0 \%$ & $10 \%$ & $48 \%$ & $36 \%$ & $6 \%$ & & & \\
\hline \multirow[t]{2}{*}{7} & Item 7 & $\mathrm{~F}$ & 0 & 41 & 56 & 3 & 0 & 338 & 500 & $67,6 \%$ \\
\hline & & $\%$ & $0 \%$ & $41 \%$ & $56 \%$ & $3 \%$ & $0 \%$ & & & \\
\hline \multirow[t]{2}{*}{8} & Item 8 & $\mathrm{~F}$ & 0 & 48 & 50 & 2 & 0 & 346 & 500 & $69,2 \%$ \\
\hline & & $\%$ & $0 \%$ & $48 \%$ & $50 \%$ & $2 \%$ & $0 \%$ & & & \\
\hline \multirow[t]{2}{*}{9} & Item 9 & $\mathrm{~F}$ & 2 & 49 & 48 & 1 & 0 & 352 & 500 & $70,4 \%$ \\
\hline & & $\%$ & $2 \%$ & $49 \%$ & $48 \%$ & $1 \%$ & $0 \%$ & & & \\
\hline \multirow[t]{2}{*}{10} & Item 10 & $\mathrm{~F}$ & 3 & 45 & 50 & 2 & 0 & 349 & 500 & $69,8 \%$ \\
\hline & & $\%$ & $3 \%$ & $45 \%$ & $50 \%$ & $2 \%$ & $0 \%$ & & & \\
\hline \multirow{3}{*}{\multicolumn{2}{|c|}{$\begin{array}{l}\text { Akumulasi } \\
\text { Jawaban }\end{array}$}} & $\mathrm{F}$ & 5 & 400 & 527 & 61 & 7 & 3335 & 5000 & $66,7 \%$ \\
\hline & & & $5 \%$ & $400 \%$ & $527 \%$ & $61 \%$ & $7 \%$ & & & \\
\hline & & $\%$ & $0,5 \%$ & $40,0 \%$ & $52,7 \%$ & $6,1 \%$ & $0,7 \%$ & & & \\
\hline
\end{tabular}

Sumber: data primer yang diolah, (2019)

Secara garis besar, letak keputusan pembelian dapat dilihat pada gambar 3.2:

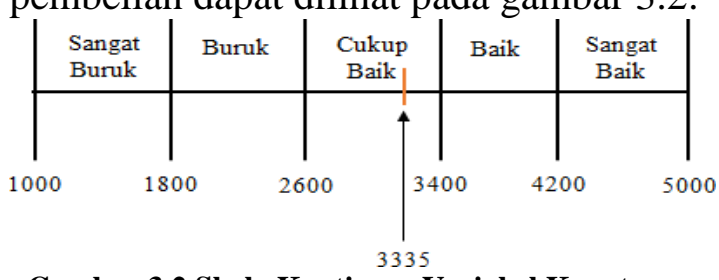

Gambar 3.2 Skala Kontinum Variabel Keputusan Pembelian

Berdasarkan gambar 3.2 diatas menunjukan bahwa data yang diperoleh dari hasil perhitungan pengkategorian untuk skor total faktor situasional terletak antara rentang 2600 dan 3400. Dengan demikian, penilaian para responden terhadap keputusan pembelian termasuk dalam kategori penilaian cukup baik.

\section{Koefisien Determinasi $\left(\mathbf{R}^{\mathbf{2}}\right)$}

Menurut Alfa, Rachmatin, dan Agustina (2017:68) mengatakan bahwa nilai koefisien determinasi (R2) dipergunakan untuk mengukur seberapa besar pengaruh variabel laten independen terhadap variabel laten dependen. Hasil R2 0,75 menunjukkan model kuat, 0,50 moderat, dan 0,25 model lemah (Hair (2011) dalam Ghozali (2014:81)). Berikut nilai R2 dilihat pada gambar 3.3: 


\section{R Square}

\begin{tabular}{|c|c|c|c|c|}
\hline \multirow{2}{*}{ Matrix } & 擭萃 R Square & 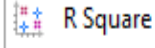 & Adjusted & \\
\hline & & R Square & RSquar & e Adjusted \\
\hline Keputusan & embelian & 0.714 & & 0.711 \\
\hline
\end{tabular}

Gambar 3.3 Koefisien Determinasi (R2)

Pada gambar 3.3 menunjukan bahwa nilai R2 (R Square) pada penelitian ini sebesar 0,714 yang berarti memiliki nilai lebih kecil dari 0,75. Maka dapat dikatakan pemodelan yang dibentuk dikategorikan sebagai model yang moderat.

\section{Hasil Analisa Hipotesis}

Menurut Ananda (2015:20) untuk pengujian hipotesa dilakukan dengan melihat nilai probabilitasnya dan tstatitisnya. Untuk nilai probabilitas, nilai p-value dengan alpha 5\% adalah kurang dari 0,05 . Nilai t-tabel untuk alpha 5\% adalah 1,95 . Sehingga kriteria penerimaan hipotesa adalah ketika t- statistik>t-tabel. Pengujian hipotesis dapat dilihat pada tabel 3.3. Berikut tabel 3.3 tentang TStatistic:

Tabel 3.3 T-Statistic

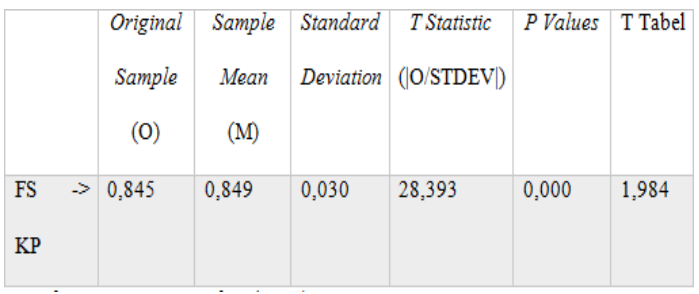

Sumber: Output Smartpls 3 (2019)

Pada tabel 4.8 menunjukan bahwa nilai $\mathrm{P}$ Values dengan alpha $5 \%$ adalah kurang dari 0,05 dengan nilai 0,000, maka dapat dinyatakan adanya pengaruh variabel independen terhadap variabel dependen. Berikut adalah gambar mengenai T-Statistic:

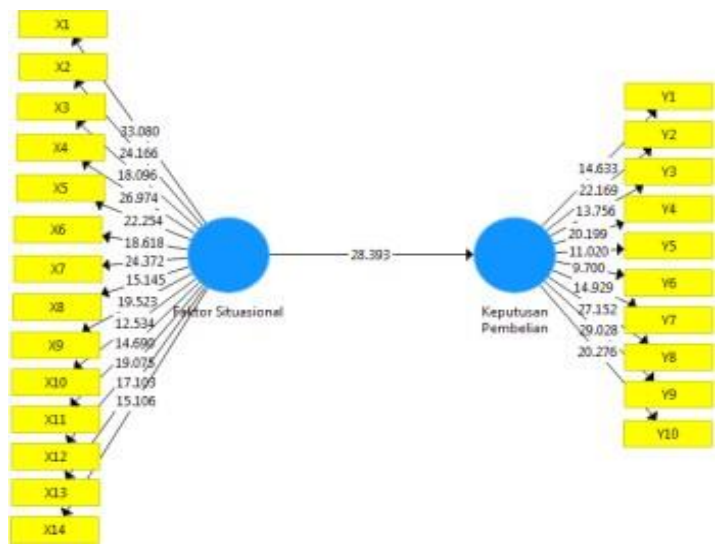

Gambar 3.4 Output Diagram Jalur T-Statistic

Dengan SmartPLS 3

\section{KESIMPULAN}

1. Tanggapan responden terhadap Faktor Situasional Konsumen Harvard English Course berada pada kategori cukup baik yaitu sebesar 4640 . Responden menunjukan bahwa kesan para konsumen Harvard English Course telah baik, dibuktikan dengan pernyataan dengan rata - rata nilai yang berada pada kategori cukup baik yang menyatakan bahwa para responden mayoritas merasa penawaran yang diberikan untuk mengikuti kursus bahasa inggris di Harvard English Course cukup menarik. Selain itu, persepsi para responden terhadap Faktor Situasional Harvard English Course dinilai telah sebanding dengan keinginan dan kebutuhan. Hal tersebut karena konsumen merasakan bahwa Harvard English Course masih dapat membuat para responden cukup puas akan jasa kursus bahasa inggris yang ditawarkan.

2. Tanggapan responden terhadap Keputusan Pembelian di Harvard English Course berada pada kategori cukup baik sebesar 3335. Responden akan mencoba merekomendasikan Harvard English Course untuk tempat kursus bahasa inggris, hal yang peneliti temukan di lapangan adalah karena harga kursus bahasa inggris di Harvard English Course yang ditawarkan murah dari segi harga sehingga responden 
akan mencoba merekomendasikan pada rekan atau kerabatnya apabila harga yang menjadi salah satu pertimbangan mereka.

3. Faktor Situasional berpengaruh positif terhadap keputusan pembelian secara signifikan yaitu sebesar 0,714 atau $71,4 \%$ maka dapat dinyatakan mempunyai model yang moderat atau sedang.

\section{DAFTAR PUSTAKA}

Alfa, Alodya Ann, Rachmatin, Dewi, Agustina, Fitriani, Analisis Pengaruh Keputusan Konsumen Dengan Structural Equation Modelling Partial Least Square. Vol. V No. 2, 2017

Ghozali, Imam, \& Latan Hengky, Partial Least Squares : Konsep, Teknik dan Aplikasi Menggunakan SmartPLS 3.0 (edisi ke-2). Semarang : Universitas Diponegoro, 2014

Hawkins, Del, I. \& Mothersbaugh., Consumer Behavior : Building Marketing Strategy (11thedition). American, New York :McGrow Hill/Irwin, 2016

Hussein, Ananda Sabil, Penelitian Bisnis dan Manajemen Partial Least Squares (PLS) dengan SmartPLS, 2015

Kotler, P., \& Keller, K.L, Marketing Management (15th edition). New Jersey : Prentice - Hall, 2016

Pagita, Rhea, \& Hariawan, P, Analisis Preferensi Konsumen Terhadap Tempat Kursus Bahasa Inggris Di Bandung. Vol. II. No.3, . 2015 